http://dx.doi.org/10.35381/r.k.v5i1.805

\title{
Análisis de la prelectura en Educación Inicial
}

\section{Analysis of the pre-reading in Initial Education}

\author{
Ruth Alexandra Peláez-Sayago \\ ruth.pelaez@psg.ucacue.edu.ec \\ Universidad Católica de Cuenca, Azogues \\ Ecuador \\ https://orcid.org/0000-0003-4046-3678 \\ Darwin Gabriel García-Herrera \\ dggarciah@ucacue.edu.ec \\ Universidad Católica de Cuenca, Azogues \\ Ecuador \\ https://orcid.org/0000-0001-6813-8100 \\ Carlos Marcelo Ávila-Mediavilla \\ cavilam@ucacue.edu.ec \\ Universidad Católica de Cuenca, Cuenca \\ Ecuador \\ https://orcid.org/0000-0002-2649-9634 \\ Juan Carlos Erazo-Álvarez \\ jcerazo@ucacue.edu.ec \\ Universidad Católica de Cuenca, Cuenca \\ Ecuador \\ https://orcid.org/0000-0001-6480-2270
}

Recibido: 24 de abril de 2020 Revisado: 29 de mayo de 2020 Aprobado: 14 de junio de 2020 Publicado: 30 de junio de 2020 


\title{
RESUMEN
}

El objetivo de este estudio fue conocer la importancia de la motivación a la lectura mediante la prelectura, puesto que la lectura, es la base de la comunicación en los individuos sin importar nivel social, cultural, político, todos estamos inmersos en el mundo de la comunicación, ya sea de forma oral, escrita, o mediante signos, todo estos a través de una revisión bibliográfica pormenorizada, los resultados permitieron evidenciar que la falta de motivación en los infantes de prescolar puede revelar abandono a la lectura en lo posterior, no solo con problemas de lectura, sino también de escritura. Se demostró que se puede ayudar al niño en la familia y escuela, mediante la motivación brindando un clima favorable donde el niño disfrute de sus experiencias prelectoras.

Descriptores: Escuela de párvulos; enseñanza de la lectura; promoción de la lectura; orientación para la lectura. (Palabras tomadas del Tesauro UNESCO).

\begin{abstract}
The objective of this study was to know the importance of motivation to read through prereading, since reading is the basis of communication in individuals regardless of social, cultural or political level, we are all immersed in the world of communication, either orally, in writing, or by signs, all of these through a detailed bibliographic review, the results showed that lack of motivation in preschool children can reveal abandonment to reading later, not only with reading problems, but also with writing. It was shown that the child can be helped in the family and school, through motivation, providing a favorable climate where the child enjoys his or her pre-reading experiences.
\end{abstract}

Descriptors: Nursery schools; reading instruction; reading promotion; reading guidance. (Words taken from the UNESCO Thesaurus). 


\section{INTRODUCCIÓN}

El problema de lectura y escritura es un hecho que se ve reflejado en la sociedad actual, visto que desde la infancia, no todos los niños/as presentan interés por conocer rasgos de lectura y escritura, en ciertos casos asimilan de manera mecánica y no de carácter atractivo en su aprendizaje, día a día se engrandece la preocupación en niños y niñas que sienten rechazo hacia la lectura, pues, carecen de comprensión lectora (PerdomoGonzález, 2011). En cuanto a este aspecto, se expresa que a nivel mundial cada tres años se aplica el Programa para la Evaluación Internacional de los alumnos (PISA), en ésta se evalúa disciplinas como: ciencias, matemática y lectura, la última evaluación se realizó en el 2015, cuyos resultados que se dieron a conocer en el año 2016 donde se destacaron en el área de lectura específicamente países como: Singapur, Hong Kong, Canadá, Finlandia e Irlanda, siendo Singapur el país más sobresaliente en esta área (Alemán, 2018).

Por lo que respecta a Ecuador, la UNICEF promueve la lectura, no obstante, existen bajos niveles de lectura en relación a otros países Latinoamericanos, por lo que, la UNESCO ha realizado varias pruebas en las que se revelan ésta problemática que conllevan los infantes y adolescentes, no cubriendo las necesidades de aprendizaje, en tal sentido, es preciso acudir a todos los esfuerzos para sembrar hábitos e interés por la lectura ya sean estos dados en el sector público o privado, todos deben brindar ayuda para un legítimo desarrollo lector (Chacha-Supe \& Rosero-Morales, 2020).

Una buena motivación a tiempo, puede generar un buen pronóstico de lectura a futuro, de lo contrario derivará probablemente un fracaso lector, debido a que la lectura es la vía principal de acceso al conocimiento, puesto que está implicada en nuestra vida cotidiana. Lamentablemente en el Ecuador no tenemos hábitos lectores, respecto a otros países, se puede relacionar con datos que se tiene sobre nuestro país, encontrándose entre los países con un nivel bajo en lectura, cabe destacar que esto se debe a varios factores, por lo que surge preocupación en el tema, ya lo dice la Constitución Ecuatoriana, sección quinta Art. 27 (Asamblea Nacional Constituyente, 2008). La educación será: participativa, democrática, incluyente y diversa de calidad y calidez y para ello se procura que desde 
la infancia el niño y niña sea atendido en cuanto al campo educativo.

Por lo que, el Ministerio de Educción a través del Currículo Ecuatoriano Curriculo Educaciòn Inicial (Ministerio de Educación del Ecuador, 2014) considera el ámbito de Comprensión y Expresión de Lenguaje, en este ámbito, se potencia el desarrollo del lenguaje en los infantes, como elemento fundamental de la comunicación, en la que el niño expresa sus ideas, sentimientos, emociones mediante símbolos verbales y no verbales, ayudando a relacionarse y desempeñarse con los demás, constituyendo estos elementos como factores sustanciales que cimentan bases para procesos futuros de lectura y al mismo tiempo de escritura, preparando un auténtico desarrollo de pronunciación, en tal sentido, en un estudio desarrollado (Zumba, 2015), manifiesta que la predisposición hacia la lectura se da desde la etapa inicial, considerando que si existe un buen estímulo ésta puede perdurar en la vida adulta, vista como un deleite propio de su persona dejando de ser vista como un deber u obligación, es decir, que conservará hábitos lectores que fortalezcan el lenguaje, educando posiblemente sensibilidad en el individuo.

Razón por la que, el objetivo del presente trabajo investigativo es conocer la importancia de la motivación a la lectura mediante la prelectura, puesto que la lectura, es la base de la comunicación en los individuos sin importar nivel social, cultural, político, todos estamos inmersos en el mundo de la comunicación, ya sea de forma oral, escrita, o mediante signos.

\section{Referencial teórico}

La lectura constituye una base fundamental en el estudiante, brindando la capacidad de emitir opiniones personales, posibilitando argumentos sobre lecturas elaboradas para el provecho de aprendizajes significativos (Alemán, 2018). Por otra parte, estimular el desarrollo cognitivo al mismo tiempo la imaginaciòn y creatividad mediante la lectura, ayuda al desarrolo linguìstico (Luna, Ramírez, \& Arteaga, 2019). El desarrollo de la lectura y escritura (Montealegre, 2006), precisa dos fases: Adquisición, esta fase presenta incomparables niveles conceptuales que se dan en edad temprana, mediante la 
curiosidad por comprender el lenguaje oral y escrito, entonces, los niños/as intentan razonar comenzando por el garabato, dibujo, juego, comprendiendo también gestos a partir de las primeras construcciones con características simbólicas, la segunda fase es la de Dominio, en esta se da una serie de procesos (preceptivos, semánticos, léxicos, sintácticos ) y estrategias (metacognitivas, inferenciales, etc.), es en esta fase, en la que se determina el dominio del sistema de escritura, en tal modo que, podemos referir que este estudio, concreta que el desarrollo del lenguaje escrito se da inicio con la prehistoria conceptual de los gestos y garabatos. En la fase de adquisición lectora se puede expresar también que encuentra en relación con la comprensión lectora. El niño/a debe estar inmerso en actividades para el logro de la decodificación, que va de la mano con la comprensión lectora, y la comprensión lectora debe desarrollarse mucho antes de que el niño/a sepa leer, dándose ésta desde etapa prescolar, periodo en que el niño/a comienza con la interpretación de palabras, laminas e imágenes cuentos que se le indica a partir de la lectura, mediante la información visual que recibe (Albuja, 2016).

La habilidad de leer en los niños/as, no se da de forma natural en sus primeros años de vida, no obstante, aparece la necesidad por aprender a leer, pero para ello requieren de una cuantiosa ayuda e instrucciones, planificaciones y métodos, los cuales, fortalecerán para el resto de sus vidas, comprendiendo de este modo, la lectura en los infantes, debe iniciarse a partir de mucho esfuerzo y dedicación, es decir, hay que persistir hasta que se convierta en un hábito en los pequeños. Respecto al párrafo anterior, se puede percibir que para que los niños/as comiencen a explorar conocimientos de lectura desde sus primeros años, es necesario el desarrollo del proceso pre lector, se dice que existe una gran relación entre las habilidades prelectoras y la lectura posterior.

(Pérez, 2017), en su estudio cita que, la lectoescritura es una etapa de complejidad en etapa inicial, pues, no sólo abarca un proceso mecánico en el que el niño codifica y decodifica, sino que, va más allá, mediante determinados niveles de maduración, como es el desarrollo de psicomotricidad, la función simbólica y afectividad, en este sentido, nos centraremos en la prelectura como estímulo a la lectura desde etapa inicial, puesto que, en la actualidad se ha observado un déficit en la lectura, por lo que, se propone 
diferentes soluciones para que el niño y niña desde etapa inicial se sienta atraído por la lectura, dando inicio con la prelectura, pues se considera la base primordial para lograr un buen desempeño en la habilidad lectora.

Siendo la prelectura la etapa más importante, puesto que, es en este periodo que se da paso a la construcción progresiva, para la adquisición de futuros conocimientos y aprendizajes, por tal razón, la prelectura debe estar presente en todo proceso de aprendizaje de nivel inicial, como un factor potenciador en el desarrollo infantil, es menester, que las docentes de los centros infantiles de prescolar tengan presente en sus actividades, ejercicios que le facilite evidenciar con frecuencia el desarrollo propio de la vista, audición y lenguaje, debido a que éstos órganos son vías que conducen de forma directa el aprendizaje, es por ello que, en el primer año de básica no se enseña directamente a leer, si no que el objetivo más bien es, practicar habilidades que den paso a una equilibrada madurez para la verdadera actividad lectora (Morocho, 2015).

\section{Prelectura}

La prelectura, es la preparaciòn que el niño/a recibe antes de dar inicio al proceso lector, mediante la cual, se facilita la comprensiòn, gracias a la adquisiciòn de informaciòn que se activa en los conocimientos previos. Es decir, que la prelectura no sòlo sirve de ayuda en la comprension lectora, si no que, aumenta el dominio de vocabulario y estructuras lingüísticas, tambièn gramaticales, si en un niño/a se logra el buen trato a los textos, superarà su autonomìa lectora y por ende su rendimiento escolar.

En virtud de ello, se obtiene información de (Flores, 2013) donde se toma como ejemplo el discurso narrativo, en el cual, se establece como la forma más usual para los niños/as en el proceso de educación inicial, hasta la educación primaria, justificando mediante la frecuencia con la que se concurre a los cuentos en la lectura y audición, estas establecen habilidades lingüísticas tomando en cuenta la valía a la Literatura Infantil, entonces, se puede articular que los infantes que se relacionan tempranamente con algún tipo de cuentos o textos, poseen un vocabulario sugerente con capacidad para decodificar, comprender y expresarse en condiciones orales y escritas facilitando la comunicación. 
Por otro lado, se sospecha que la falta de interés por la lectura correspondería a la manera de enseñanza tradicional brindada por las/ los docentes, como se detalla en el estudio de (Torres, 2016), en el que se ejemplifica a cierta docente que se encuentra sentada en el centro de una mesa redonda, los niños se encuentran en la parte espaldar de la maestra, no están prestando atención, por falta de visibilidad, la incorrecta ubicación de la maestra hace que los niños/as de inmediato pierdan interés por el cuento, dando paso a que se dediquen a realizar otras actividades no inmersas a la actividad que desarrolla la educadora, sino que, se dedican a jugar, pelar, dar gritos, entre otros, la falta de contacto visual, hace que los estudiantes no se sientan identificados con la lectura, este método resulta ser inadecuado, carente de estrategias didácticas, la falta estrategias lúdicas en el aula difícilmente animará a los niños/as de prescolar a sentirse atraídos por la lectura y esta falta de atracción por el hábito lector, desencadenará conocimientos de aprendizaje negativos, por lo que, todas la áreas están vinculados con la lectura .

Así también en lo que respecta al Sistema Educativo, los docentes asisten en la educación de los infantes, lo cual, debe darse mediante una planificación bien organizada, para desarrollar las actividades en el aula, la falta de estrategias lúdicas por parte del docente repercuta en los estudiantes con carencia de vocabulario y comprensión lectora, ya que las habilidades lectoras se inician desde edad muy temprana, un buen estímulo de lectura potenciará un enriquecimiento lector, esto se puede dar marcha a partir del aprestamiento lecto-escritor. Se debe permitir al niño la observación de todo cuanto hay a su alrededor el mayor tiempo posible, para que el niño despierte el deseo de aprender, manifestándose de acuerdo a las experiencias que al niño le favorezcan, mediante experiencias transmitidas ya sea en el hogar o escuela.

Por otra parte, se consigue datos informativos obtenidos en esta investigación, en la que se puede analizar y comparar las diferentes propuestas de estrategias para incentivar la lectura desde edad temprana, considerando que la lectura es un factor importante en todo individuo por tanto, se debe dar real atención en todos los espacios, partiremos desde reflexionar que la lectura se da a partir del segundo grado de educación básica en edades comprendidas entre cinco, seis y siete años promedio, pero cabe señalar que los 
niños en edades inferiores no logran leer aún, pero si pueden comprender mediante señales, grafías, signos y sonidos, a lo cual se le denomina prelectura, respecto a ello disponemos de contextos en que se menciona que, el aprendizaje se da desde mucho antes de nacer, mediante la aspectos como la estimulación prenatal, se puede estimular mediante diversas formas, por ejemplo mediante la música: La madre en estado de gestación puede elegir música variada y colocar en su vientre, esto ayudará en la estimulación cerebral, la madre debe examinar la música que le pueda hacer vibrar en su sintonía. Entonces vibrará también el bebé en su interior, así compartirán juntos una experiencia gratificante. (Federico, 2004), en torno a ello, la música se convierte en un puente que enlaza el vínculo madre-hijo antes del nacimiento, es algo muy interesante que se cita en el libro llamado Melodías para él bebé antes de nacer. Las canciones con letra activan las áreas del cerebro, en cuanto al aspecto metal e intelecto, así lo demostraron investigadores Sloboda, Tylor y Deliegue, a diferencia de las canciones compuestas sólo por sonidos, es decir, sin letra, favorecen a la regulación de emociones, ésta herramienta puede servir de mucha ayuda para que las madres tomen en cuenta y puedan estimular desde que se encuentran en etapa de gestación.

Algo relacionado a ello, se verifica en otro estudio, en el cual se expresa que. el cerebro de un infante es asombroso y sorprende entre los 0 y 3 años de edad, pues, comprende la mayor plasticidad cerebral que engloba la sinapsis en su conexión de células nerviosas, construyendo una red de circuitos eléctricos neuronales, posibilitando el aprendizaje, la actividad cerebral entre 0 y 2 años duplica la de un adulto, en este periodo todo estímulo es absorbido por el infante de acuerdo a su entorno y el aprendizaje pasa a ser resultado de la interacción dispuesta por las experiencias recibidas y su potencial genético, lo cual ayudará a afrontar su futuro (Flores, 2013).

Por lo que, se puede anotar claramente que, mientras más acertada y temprana sea la estimulación en el niño/a, éste derivará condiciones positivas en el desarrollo y crecimiento, como ya lo habíamos señalado en el párrafo anterior, guarda concordancia con (Flores, 2013). Los factores ambientales positivos en el desarrollo de los primeros años de vida, su sistema nervioso se desplegará en excelentes condiciones debido a que 
el desarrollo cerebral se da antes de los dos años, siendo en este lapso corto que alcanza la capacidad de pensar, aprender y hablar, ligados a los comportamientos sociales los cuales determinaran su vida.

Como podemos ver, las informaciones de los autores concuerdan en que se debe estimular desde antes de nacer, así el infante va adquiriendo destrezas en cuanto al intelecto, fortaleciendo todas las áreas (Dovale, 2018). De este modo, continuamos con información relevante a partir de la estimulación del lenguaje, desde el primer mes del nacimiento, en este aspecto (Perdomo-González, 2011). Recomienda a partir del primer mes de nacido el niño/a, familiarizar con el lenguaje humano, estimulando con la expresión de sonidos, emociones, generando improntas primordiales de la comunicación mediante el lenguaje, para ello, presenta actividades que sirvan de ayudantía a las madres, y personas encargadas del cuidado del niño/a:

Manifiesta que: En el momento en el que él bebé es bañado, vestido o alimentado, se recomienda hablarle como si se hablaría con cualquier otra persona, imitando sonidos guturales que el pequeño emite, esto hará que el bebé al momento de escucharlos se sienta motivado para a su vez reactivarlos, incrementando el adiestramiento en su aparato fonador.

Se sugiere fortalecer signos de alegría manifestados por el niño, aceptando como parte de su desarrollo, considerando los periodos de llanto que suelen presentarse como algo natural y no obedecen a malestar alguno.

Se debe tomar en cuenta el silencio, como parte del lenguaje, no es correcto perturbar al pequeño en sus momentos de silencio, es muy probable que disfrute de su bienestar. En la siguiente actividad se va a estimular el lenguaje gestual, esta actividad es recomendada a partir de los cuatro meses de nacimiento y durante los primeros tres años de vida.

En esta etapa es conveniente estimular la familiarización del lenguaje gestual, estimulando a la vez la expresión de emociones mediante la mímica, generando huellas que sirvan de complemento al leguaje oral. 
La actividad consiste en mostrarle gestos al bebé, trabajando con la boca, ojos, nariz gradualmente, para luego integrar sonidos con manos y movimiento corporal, el bebé manifestará mucha atención ante estas conductas, permitiéndolo conocer la flexibilidad de rostro y cuerpo que, con seguridad iniciará la imitación de gestos, de acuerdo al modelo gestual emitido por el estimulador. Posteriormente, entre los dos y tres años ya se puede pedir que haga imitaciones, expresando en su rostro varios estados de ánimo, como poner carita feliz, carita triste y de enojo.

Continuamos con ejercicios mediante sonidos, en esta etapa, se propone el fortalecimiento de la articulación de sonidos básicos del lenguaje, este periodo se recomienda entre el año y medio y dos años, aquí se propone trabajar en el progreso del dominio articulatorio, se realiza ejercicios mediante movimientos de la lengua. El adulto emite sonidos para que el niño pueda observar y escuchar y se le propone articular vocales, consonantes y silabas realizando los sonidos variadas veces, luego de ello, se hará la corrección de las pronunciaciones incorrectas emitidas por el pequeño, se corrige rectificando lo que el niño ha emitido incorrectamente.

Otra actividad recomendada para la ejecución de la fonación es, el trabajo por medio de la utilización de títeres, el objetivo es, experimentar la comunicación a partir de la palabra hablada, preparando la fonación de palabras para la posibilidad de un diálogo regocijante. Se expone los títeres, a niños de edad comprendidas entre año y medio a dos o nivel de desarrollo equivalente, en esta edad los infantes no discriminan realidad-fantasía por lo que les resulta muy llamativos los actores y ponen interés en ello, es en ese momento en que, el estimulador realizará conversaciones, comunicando el nombre del personaje, contando una historia o entonando una canción, e introduciendo al diálogo niño-títere, se formulará preguntas sobre su nombre, edad, nombre de sus padres, abuelos.

Ahora expondremos ejercicios para un vocabulario divertido, también sugerido para niños entre año y medio a dos años o con un nivel de desarrollo similar, lo que se desea es inducir al infante al lenguaje oral, con una acertada pronunciación, ampliando su vocabulario a partir de la palabra hablada. La realización de esta actividad partirá desde, armar una plancha con una variedad de imágenes del medio, con ellas la persona 
encargada de estimular pronunciará correctamente las palabras de las imágenes, Ejemplo: Palabra correcta: auto; incorrecto "pi- pi". Otro ejercicio, es trabajar con material u objetos concretos, indicando que objeto es, por su color, forma. Otra opción, es trabajar mediante láminas ya con una temática, pudiendo ser sobre animales, colores, frutas, figuras, entre otros.

Una vez trabajado todas las actividades indicadas, se propone, incitar el diálogo trabajando en el dominio del vocabulario, partiendo de la realidad en base a preguntas, proporcionando el disfrute en espacios de comunicación, destinando un espacio a diario para una conversación con el niño/a, éste es un recurso muy importante para la comprensión, el niño/a se animará a la formulación de un sin número de interrogantes, mediante la percepción, observación y conceptualización.

Seguido a las actividades presentadas, se expone la hora de los cuentos, en este espacio, se genera la percepción, atención y trasmisión de mensajes ejercitando el dominio del lenguaje, se recomienda utilizar historias breves, con un contenido de muchas imágenes, en lo posible mediante ritmo, sonido, e imágenes sensoriales, se puede crear sus propias historias en conjunto con el pequeño, estas actividades se trabajarán a lo largo de su infancia. Como se ha podido observar, todas las actividades tienen un propósito en la estimulación y se fomenta el intelecto mediante del área cognitiva y partir de ello, se enlaza el lenguaje, comunicación de emociones, sensaciones, y motivación hacia la lectura desde edad una edad muy corta.

En relación a ello, se presenta otro estudio en el que, se sostiene que, el desarrollo de las habilidades lingüísticas y cognitivas en la educación prescolar da un pilar sólido para el aprendizaje del lenguaje, en esta fase de aprestamiento prescolar, se brinda respuestas en los lineamientos para la atención a la primera infancia, partiendo desde los tres años de edad, con prácticas en cuanto a la estimulación que debe recibir el niño/a previa a la enseñanza de lectura y escritura, cabe anotar que esta motivación, surge por la necesidad que presentaban las docentes por buscar mejoras en sus prácticas pedagógicas, haciendo ahínco en la conciencia fonológica que también es un punto importante a tratar, pues, visto desde este punto, la conciencia fonológica y desarrollo 
lector (Varela, 2014), se revela con el uso apropiado de herramientas, las cuales estimulen las habilidades metalingüísticas en edad temprana, lo que favorece en el éxito del desarrollo en el proceso de lectura y escritura (Almeida, et al., 2020).

\section{Conciencia fonológica}

En cuanto a la conciencia fonológica presentamos una definición en la que se puede considerar en el desarrollo lingüístico infantil. La conciencia fonológica por parte de Valdivieso, 2004. Consiste en habilidades metalingüísticas los cuales consienten al niño/a el proceso de componentes fonéticos de lenguaje oral (Albuja, 2016).

Se considera otra línea de investigación revisada, en la que utiliza un diseño experimental, donde se pretendía comprobar si el adiestramiento de habilidades fonológicas en los niños y niñas mejoraba su rendimiento lector en relación a otros no entrenados, Fox y Ruth, 1976, tomaron una investigación con 40 niños de 4 años, a quienes se les proporcionó una mezcla de sonidos asociándolos a símbolos parecidos a letras, el resultado mostró el efecto del adiestramiento con la mezcla de sonidos en la lectura, pero este resultado se dio en aquellos niños que solo resultaban hábiles en tareas de segmentación, años más tarde en 1984 Fox y Ruth vuelven a estudiar la influencia sobre varias tareas de segmentación y mezcla de sonidos con un grupo de 41 niños de prescolar, en el que obtuvieron resultados relevantes (Delfior, 1994).

Otras explicaciones, describen actividades didácticas que ayudan en el desarrollo de la conciencia fonológica donde se evidencia que la lectura da inicio con el lenguaje, por ello se considera que el rendimiento lector se predice de un origen ligústico (Porta, 2012).

Por otro, se expresa sobre el arte del lenguaje mediante la literatura en etapa inicial, teniendo gran significado en los seres humanos puesto que, desde el nacimiento o antes todos los individuos están ligados al lenguaje y literatura pudiendo ser representadas por melodías, imágenes y vocabulario, brindando beneficios en el desarrollo, cognitivo, emocional, lingüístico y cultural (Córdoba, 2017). Antes de saber leer, los niños/as que se beneficiaron de animaciones de lecturas habituales, poseen comportamientos distintos, tienen familiaridad con libros y cuentos, Bonnafè. Se considera la literatura 
como una vía importante en el desarrollo integral en primera infancia del infante, lo cual, facilita la comprensión de todo cuanto lo rodea.

Por otra parte, se expresa que si bien es cierto, el estímulo hacia la lectura debe iniciarse desde edad muy temprana, poniendo en práctica con la prelectura, siendo los responsables en este proceso los padres y cuidadores de los niños y niñas, hasta llegar a la etapa escolarizada donde ya entran en relación con docentes, en tal sentido, el docente es quien está a cargo de impartir estrategias metodológicas significativas respecto a la temática, sin embargo, surge la preocupación sobre la práctica diaria del docente, pues, en algunos casos se observa un limitado esfuerzo por parte del sector educativo, (Flores, 2013) en su investigación denota la falta de estrategias motivantes para la comprensión lectora, (Fajardo, 2018). Asì tambièn, existen docentes que no le prestan real importancia a la lectura en el proceso acadèmico, ignoran el uso de recursos y materiales didàcticos, que deben brindar a los niños y niñas para que a su vez, brinden resultados òptimos en el dearrollo del habito de lectura, los docentes son monòtonos y rutinarios, propiciando un nivel de rendimiento acadèmico bajo (García, Macias, \& Cusme, 2016).

Se han incrementado investigaciones relacionadas a la lectura en educación inicial, con la finalidad de obtener un nivel más alto de lectores, con capacidad de reflexionar y disfrutar de la lectura, cabe recalcar que, existe muy poca socialización en los canales científicos investigativos en cuanto a la enseñanza de la lectura en la primera infancia, por lo que, es de vital importancia, dar a conocer contenidos sobre estas investigaciones en los campos educativos, para mantenerse informados sobre lo que en la actualidad acontece, en el campo de la lectura, dato que se ve reflejado en el estudio de (Fajardo, 2018).

\section{MÉTODO}

La metodología de la presente investigación es de tipo documental con diseño bibliográfico, por lo que se diferenciaron estrategias de trabajo, cimentadas en bases científicas, teóricas y bibliográficas, conforme a la ley se establece, con ello, se procuró 
conocer aspectos relevantes sobre la prelectura encaminados hacia la lectura, con la finalidad de brindar ayuda a los docentes, padres de familia y cuidadores de los infantes (Borregales, 2020).

Brindando pautas para la introducción asertiva en la lectura desde etapa la etapa prescolar, mediante un correcto entrenamiento, para en lo posterior, alcanzar una afinidad lectora (Calle-Abril, Erazo-Álvarez, \& Narváez-Zurita, 2020), se utilizó una ficha bibliográfica en la que reposa toda la información extraída de fuentes científicas como: libros físicos, artículos de revista, libros virtuales, entre otros, todos han aportado en la recolección de información brindando contenidos relevantes sobre diferentes posturas, que han permitido desarrollar un análisis de datos verídicos (Cuello-Cojitambo, ErazoÁlvarez, \& Narváez-Zurita, 2020).

\section{APORTES GENERADOS}

El presente artículo se aborda desde aportes generados en los que se data que: Existen factores que no son desarrollados correctamente, no hay una buena motivación para los niños/as hacia la lectura, es decir, guiados por el proceso de prelectura, como se sustenta en uno de los estudios revisados, el tema de la prelectura está en un nivel bajo por los estudiadores, existe escasa información sobre el tema de prelectura y ante este escenario surge una interrogante. ¿Por qué no se está tratando el tema?

El hecho de pensar que la lectura se da desde el primer grado de escuela y que es allí donde se debe motivar al niño/a hace que los padres y cuidadores no den mucha importancia a la prelectura, siendo sólo ciertos casos los que por razones de trabajo han llevado a los niños/as al cuidado de centros infantiles y han conocido sobre el tema y la importancia de su estimulación, es en estos espacios que las docentes influyen con diferentes modelos de cuidado en el infante, trabajan las diferentes áreas cognitivas, y con ello el hecho de trabajar la motivación de prelectura mediante cuentos, rimas, sonidos, gestos, imágenes.

Es decir, se enfrentan a varios escenarios que pueden influir el diario vivir, lo cual, al ser bien entrenadas pueden dar resultados positivos a futuro, caso contrario el niño/a 
presentará problemas de lenguaje, desinterés lector, problemas de escritura, ortografía, entre otros. Los niños son espectadores de todo cuanto hay en su medio, entonces, si están en relación constante con elementos motivadores, estos incidirán en el desarrollo y crecimiento, es por ello que, en este contexto se da a conocer la importancia que tiene la problemática a resolver, anteriormente mencionadas.

Las características del entorno familiar nulas en estimulación pre lectora son factores influyentes en el desarrollo lector del niño, acarreando barreras en el proceso lector. Los padres de familia y cuidadores, deben conocer la importancia de estimular la lectura desde edad temprana y que la prelectura es una herramienta base para el inicio de la lectura.

Los docentes deben estar capacitándose constantemente para el desarrollo de habilidades y destrezas, puesto que, facilita el buen desempeño dentro del aula, le corresponde también, organizar experiencias de aprendizaje que atenúen una atmósfera de disfrute, fortaleciendo el aprendizaje del niño y niña. Es por eso que, para mejorar el desarrollo de la prelectura, desde nivel inicial, debemos influir mediante técnicas de prelectura llamativas para los niños y niñas. En primer lugar, se debe designar un espacio en el hogar y escuela con objetos relacionados a la lectura como:

Cuentos sencillos con imágenes llamativas, los cuales por su contenido colorido llaman la atención visual del infante.

Cuentos con sonidos, estos a su vez atraen por su sonido a través de ella podemos trabajar en base a la lectura rítmica, favoreciendo ésta el desarrollo de los sentidos vista, oído, tacto.

Revistas infantiles, sirven de gran ayuda ofreciendo sus contenidos para colorear. Periódicos con caricaturas, al poseer gran cantidad de gráficos, es una buena alternativa. Libros de historias infantiles, es este el medio más conocido de trasmisión de conocimientos infantiles, mediante su contenido visualiza obras plasmadas de personajes como: Hadas, princesas, animales fantásticos, monstruos, es decir, una gama de entretenimiento estético, para el deleite infantil.

Álbum de fotografías familiares con mensajes, ayudan en cuanto al área afectiva, en ellas 
podemos escribir palabras de amor para luego leerlas, trasmitiendo el sentimiento de afectividad, afianzando lazos familiares.

Cuentos mediante pictogramas, siendo herramientas con las que los niños/as comienzan a descifrar significados de imágenes, consiguiendo una recepción gradual pre lectora, introduciendo en lo posterior al mundo lector.

Fábulas, resultan ser estos una buena ruta para el entrenamiento educativo pre lector en nivel inicial, pues, nos brindan mensajes ilustrativos e imaginarios a partir de sus personajes que resultan ser en su mayoría animales o elementos ficticios.

Herramientas tecnológicas, al ser esta una herramienta con una amplia gama de presentaciones interactivas y dinámicas fortalece la velocidad del habla mediante juegos de sonidos, videos agradables, los que contribuyen la imitación de lo que él niño/a ve escucha, inspirando al descubrimiento de su propio lenguaje lo que va desarrollando el interés pre lector y por ende favorecerá al proceso lector.

A través de todos estos materiales, se despertará el afán pre lector, disfrutando de las actividades brindadas, ya sea en el hogar, centros infantiles, o instituciones educativas, cabe mencionar que las actividades afines a la prelectura deben ser desarrolladas diariamente, ya que desde allí radica el perfeccionamiento del lenguaje y con ello el afianzamiento lector. En conclusión, para que haya un buen desenvolvimiento lector, es de vital importancia que desde edad temprana se entrene la prelectura consiguiendo resultados fructíferos, para la toda la vida.

\section{FINANCIAMIENTO}

No monetario.

\section{AGRADECIMIENTO}

A la Universidad Católica de Cuenca, por motivar y apoyar el desarrollo de la investigación. 


\section{REFERENCIAS CONSULTADAS}

Albuja, M. (2016). El reconocimiento visual-ortográfico en el desarrollo de la lectura inicial de niños y niñas de Primer año de Educación Básica de la "Unidad Educativa Mario Cobo Barona [Visual-orthographic recognition in the development of the initial reading of boys an]. Ambato: UTA. Obtenido de https://n9.cl/wlrht

Almeida, V., Vilas-Boas-Barreto, B., \& Alves-Argollo, R. (2020). Comunicación y Educación: La potencia dialógica del audiovisual. [Communication and Education: The dialogical power of audiovisuals]. EPISTEME KOINONIA, 3(5), 122-141. http://dx.doi.org/10.35381/e.k.v3i5.682

Alemán, M. (2018). El papel de la lectura en la formación académica de los estudiantes de educación general básica: una experiencia desde el Ecuador [The role of reading in the formation of general basic education students: an experience from Ecuador] . OpuntiBrava, 278-285. doi:https://doi.org/10.35195/ob.v9i2.169

Asamblea Nacional Constituyente. (2008). Constitución del Ecuador [Constitution of Ecuador]. Obtenido de https://n9.cl/hd0q

Borregales, L. (2020). Génesis y evolución socio-histórica de la macro categoría cultura escrita. [Genesis and socio-historical evolution of the macro category written $\begin{array}{llll}\text { culture]. } & \text { EPISTEME } & \text { KOINONIA, } & 3(5),\end{array}$ http://dx.doi.org/10.35381/e.k.v3i5.529

Calle-Abril, D. R., Erazo-Álvarez, J. C., \& Narváez-Zurita, C. I. (2020). Estrategias de mediación y solución de conflictos para el sector industrial de pinturas [Mediation and conflict resolution strategies for the paint industry]. Revista Arbitrada Interdisciplinaria Koinonía, 514-544. doi:http://dx.doi.org/10.35381/r.k.v5i10.704

Córdoba, H. P. (2017). Pilares de la educación inicial: mediadores para el aprendizaje [Pillars of Early Childhood Education: Mediators for Learning]. JSR Funlam J. Students'Res., 91-98. doi:https://doi.org/10.21501/25007858.2582

Cuello-Cojitambo, J. D., Erazo-Álvarez, J. C., \& Narváez-Zurita, C. I. (2020). Visión sistémica de la gestión del conocimiento en el sector financiero cooperativo [Systemic vision of knowledge management in the cooperative financial sector]. Revista Arbitrada Interdisciplinaria Koinonía, 607-637. doi:http://dx.doi.org/10.35381/r.k.v5i10.707 
Chacha-Supe, M., \& Rosero-Morales, E. (2020). Procesos iniciales de enseñanza aprendizaje de la lectoescritura en los estudiantes del nivel de preparatoria. [Initial teaching-learning processes of literacy in high school students]. Revista Arbitrada Interdisciplinaria Koinonía, 5(9), 311-336. http://dx.doi.org/10.35381/r.k.v5i9.650

Delfior, S. (1994). La consciencia fonológica y la adquisición de la lectoescritura [Phonological awareness and the acquisition of literacy]. Infancia y Aprendizaje, 91-114. Obtenido de https://n9.cl/lcir9

Dovale, Y. (2018). Las habilidades resuntivas de ensayos académicos expositivos en estudiantes de la Universidad Nacional Experimental Francisco de Miranda. [The residual skills of expository academic essays in students of the Francisco de Miranda National Experimental University]. EPISTEME KOINONIA, 1(1), 18-34. http://dx.doi.org/10.35381/e.k.v1i1.488

Fajardo, L. (2018). La enseñanza de la lectura en la educación inicial. Un panorama a partir de la revisión de la literatura académica en los últimos 20 años [Teaching reading in initial education. An overview from the review of academic literature in the last 20 years]. Bogotá: Javeriana. Obtenido de https://n9.cl/ndgx

Federico, G. (2004). Obras para futuros padres [Works for future parents]. En G. Federico, Melodias para el bebè antes de nacer (págs. 14- 15-17-30). Buenos Aires: Kier. Obtenido de https://n9.cl/ff8d

Flores, J. (2013). Efectividad del programa de estimulación temprana en el desarrollo psicomotor de niños de 0 a 3 años [Effectiveness of the early stimulation program in the psychomotor development of children from 0 to 3 years old]. Ciencia $y$ Tecnología, 363-380. Obtenido de https://n9.cl/hk5u

Luna, H., Ramírez, C., \& Arteaga, M. (2019). Familia y maestros en el proceso de enseñanza-aprendizaje de la lectoescritura. Una responsabilidad compartida [Family and teachers in the teaching-learning process of literacy. A shared responsibility]. Conrado, 207-221. Obtenido de https://n9.cl/b63uc

Ministerio de Educación del Ecuador. (2014). Curriculo Educación Inicial [Initial Education Curriculum]. Obtenido de https://educacion.gob.ec/educacion-inicial/

Montealegre, R. (2006). Desarrollo de la lectoescritura: adquisición y dominio [Development of literacy: acquisition and mastery]. Bogotá: Universidad Católica de Colombia. Obtenido de https://n9.cl/28ot 
Morocho, M. (2015). Métodos y técnicas que utilizan las maestras y su incidencia en el aprendizaje de la prelectura de los niños y niñas del primer año de educación general básica [Methods and techniques used by teachers and their impact on the pre-reading learning of boys and girls in the first year of basic general education]. Universidad Nacional de Loja. Obtenido de https://n9.cl/bufqc

Perdomo-González, E. (2011). La estimulación temprana en el desarrollo creativo de los niños de la primera infancia [Early stimulation in the creative development of early childhood children]. Varona, 29-34. Obtenido de https://n9.cl/e5j4

Pérez, M. (2017). Factores y dificultades que intervienen en la adquisición de la lectura y escritura en los niños de primer año básico del colegio San Andrés de Peñaflor [Factors and difficulties that intervene in the acquisition of reading and writing in children of the]. Universidad Mayor. Obtenido de https://n9.cl/okkss

Porta, M. (2012). Un programa de intervención pedagógica en conciencia fonológica [A program of pedagogical intervention in phonological awareness]. Orientación Educacional, 93-111. Obtenido de https://n9.cl/iquh

Torres, H. (2016). Proyecto de Investigación de Aula Estrategia Didáctica para Motivar la Lectura de Cuentos en Niños de Preescolar [Classroom Research Project Didactic Strategy to Motivate the Reading of Stories in Preschool Children]. Universidad de Cartagena. Obtenido de https://n9.cl/8fk2k

Varela, V. (2014). Diseño y ejecución de actividades para la estimulación en conciencia fonológica en los niveles de prejardín y jardín [Design and execution of activities for stimulation in phonological awareness in the pre-garden and garden levels]. Estudios Superiores en Educación, 47-58. Obtenido de https://n9.cl/yv45

Zumba, L. (2015). Beneficios de la pre-lectura mediante el uso de pictogramas en niños y niñas de 3 años de edad: guía con actividades [Benefits of pre-reading through the use of pictograms in 3-year-old boys and girls: guide with activities]. Instituto Tecnológico Cordillera, 20. Obtenido de https://n9.cl/f25o 